\title{
Intraoperative Anatomical Surface Marking and Cone Beam Computerized Tomography for Assessment of the Hamulus in Palatoplasty by Younger Cleft Surgeons
}

\author{
Bergonzani $\mathbf{M}^{1}$, Uy $\mathbf{V}^{2}$, Zeinalddin $\mathbf{M}^{3}$ and Lotha $B^{4 *}$ \\ ${ }^{1}$ Maxillo-Facial Surgery Division, Parma University Hospital, Italy \\ ${ }^{2}$ OMS Resident, OMF hospital, Ho Chi Minh, Vietnam \\ ${ }^{3}$ Craniofacial Orthodontist Star Care Hospital, Senior Lecturer Oman Dental \\ College, Oman \\ ${ }^{4}$ Craniofacial Cleft Surgeon, Yemen Global Smiles, Sanaa, Yemen \\ *Corresponding Author: Lotha B, Craniofacial Cleft Surgeon, Yemen Global \\ Smiles, Sanaa, Yemen.
}

Received: June 17, 2020

Published: July 02, 2020

(C) All rights are reserved by Lotha B., et al.

\begin{abstract}
Understanding the surface anatomy markers for the hamulus in palate surgery is often a useful pointer to the position of the hook of hamulus during cleft palate surgery. This innovative idea is of particular use in Veau 1 and 2 where only medial incisions are used. Younger cleft surgeons feel more comfortable when they are able to clearly see palate structures during careful dissection. Using the intraoperative method of marking out the position of the hamulus makes the whole process of identifying the hook of hamulus a lot simpler. Drawing a vertical line from the mid tuberosity which intersects a horizontal from the level of the posterior spine, the hamulus which lies a few mm below and medial to the intersection, can easily be found. We divide each region into clockwise zones 1 , 2, 3, 4 and found the position to be consistent in zone 4, slightly medial and below the intersection of the two lines. This finding was also noted on cone beam CT images of adult and pediatric palates.
\end{abstract}

Keywords: Hamulus; Palatoplasty; Cleft Palate Training

\section{Introduction}

We would like to propose intraoperative markings for easy detection of the Hamulus position during cleft palate surgery by younger cleft surgeons, using a rather refined approach to the hook, as opposed to the clumsier index finger palpation of a sensitive spot. One would imagine that there is a significant difference between the chubby index finger of a palate connoisseur, albeit more experienced, and a laser pointer in the medical world. For obvious reasons, it is unjustifiable to equate the two. The markings are especially helpful for Veau Types 1 and small Type 2, where one uses a medial incision only with a small z plasty of the soft palate mucosa and muscle [1]. However, it can also be used for two flap palatoplasty. Medial incision only advocated by Piggot before 1987, has been used for selective cases. Larger defects would do better with lateral incisions to prevent tension or possible breakdown. The medial only incision is good for Veau type 1 and in some cases, type 2, for surgeons with more experience. Saline hydro dissection makes the closure a lot easier as a result of tissue distension, and has been used by many surgeons [2,3]. Hamulus fracture is done by some surgeons, while others avoid it. No statistically significant differences are seen with or without fracture [4]. The Hamulus lies in an exposed position at the distal end of the upper dental arch; the presence of a bursa suggests that it may be prone to irritation and bursitis. The average inclination from the sagittal plane is about 75

Citation: Lotha B., et al. "Intraoperative Anatomical Surface Marking and Cone Beam Computerized Tomography for Assessment of the Hamulus in Palatoplasty by Younger Cleft Surgeons". Acta Scientific Dental Sciences 4.7 (2020): 150-153. 
degrees and 58 degrees in the frontal plane. Children have a smaller Hamulus than adults, although the shape is similar; the type found in adults is similar in children [5]. We used CBCT images of an adult and child to pinpoint the position of Hamulus.

3D CT avoids superimposition and provides clearer visualization of the craniofacial structures with more precision than the $2 \mathrm{D}$ methods [6].

\section{Technique}

Surface marking for the Hamulus in button whole palatoplasty. For button hole palatoplasty, draw a vertical line from the mid tuberosity which intersects a horizontal from the level of the posterior spine. The Hamulus which lies a few $\mathrm{mm}$ below and medial to the intersection, can easily be found. The space of Ernst lies lateral to the Hamulus and enables the operator to shift the tissues medially thereby easing closure without tension on the medial flaps.

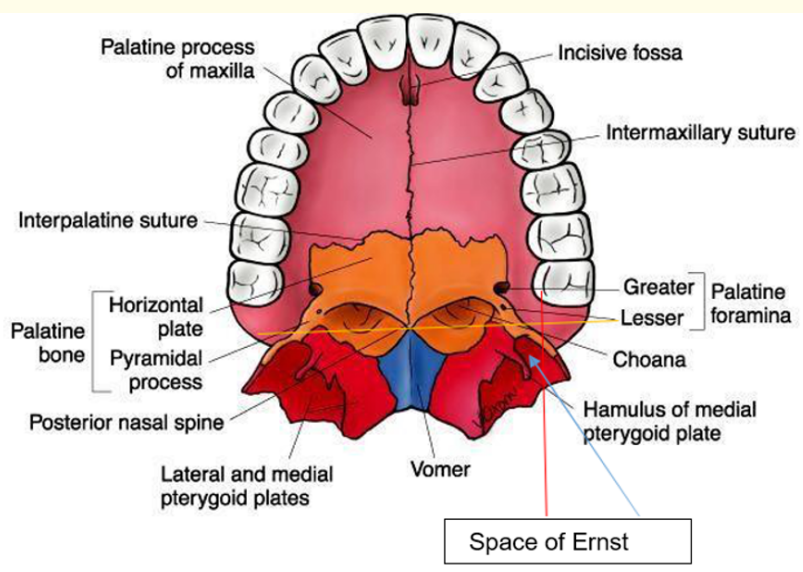

Figure 1: Anatomy of hamulus and hard palate.

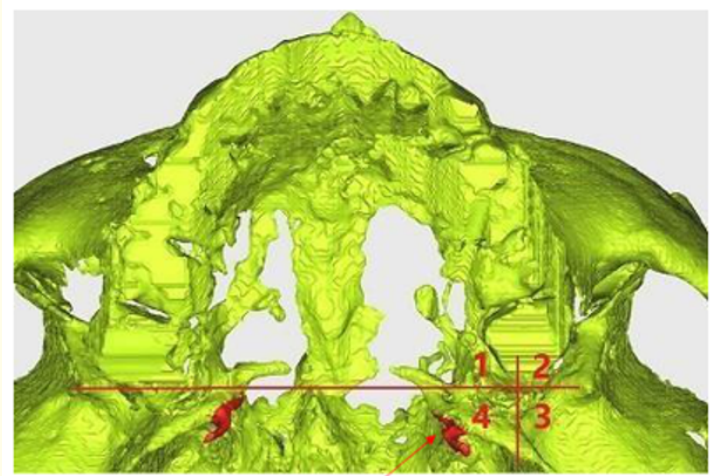

Hook of Hamulus

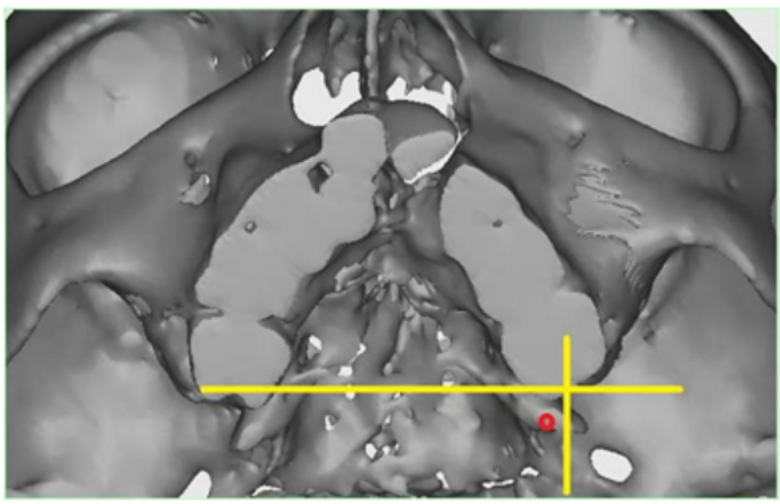

Figure 2: Adult hamulus. Courtesy M. Zeinalddin and M. Bergonzani.

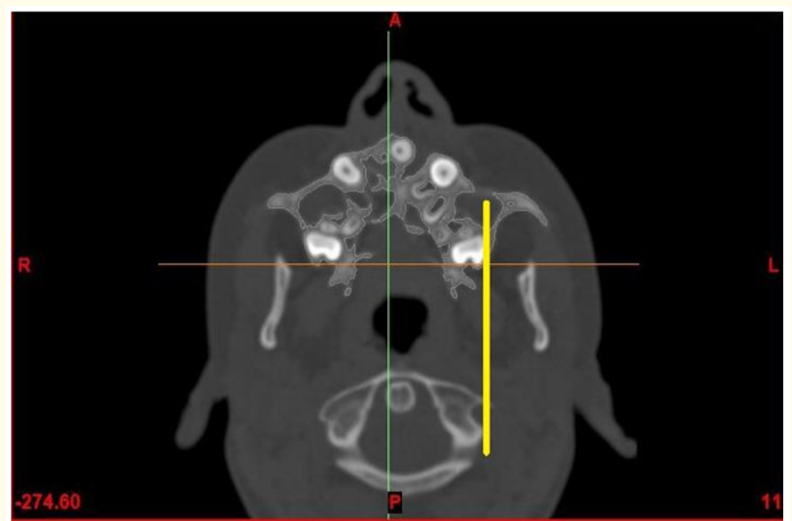

Figure 3: Hamulus in a child. Courtesy M. Zeinalddin and M. Bergonzani.

The CBCT image of an adult and cleft child. The Hamulus is consistently found in zone 4 in both the images which was confirmed intraoperatively in cleft palate children as well.

\section{Results}

The position of the Hamulus is found, using the markers as in the figure. We divide each region into zone 1, 2, 3, 4. The position of the Hamulus is found to be consistent in zone 4 , slightly medial and below the intersection of the two lines. We have tried to palpate the Hamulus using the index finger, but this is a subjective and oft clumsy approach to a sensitive spot. 

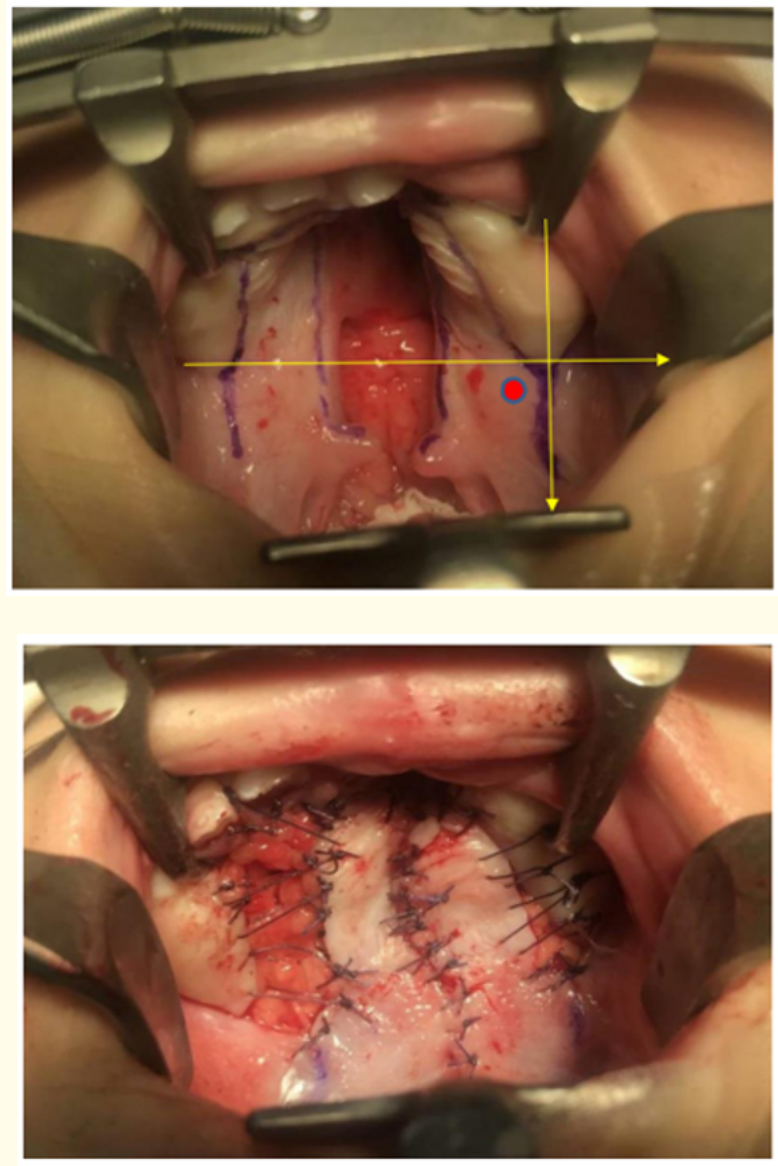

Figure 4: Intraoperative marking, confirms the position of the Hamulus in Zone 4 (Courtesy V. Uy). The red dot in zone 4 is a pointer to the hook of Hamulus.

\section{Discussion and Conclusion}

Authors are aware that this idea is one of several ways of finding the Hamulus position. There is nothing new under the sun, when it comes to cleft surgery.

All of us are involved in reinventing the wheel, in one way, or the other. In our case, one could refer to this innovation as yet another refined spoke in the palate bandwagon of serial experts. A technique oriented paper arguably relays information that is likely known to most cleft surgeons. Other skilled plastic surgeons may question the need for such technical detail, mentioning that they can find the structure easily, even by index finger palpation. On the contrary, this is not the case for younger cleft surgeons, whose surgical index fingers are still in an evolutionary phase. Veteran cleft surgeons may be skeptical of computer algorithms and ratios, which are considered interesting academic exercises, arguing that there really isn't much of a need for it.

This method offers a useful pointer to the position of the hook of Hamulus during cleft palate surgery by younger surgeons. It is of particular use in Veau 1, 2 where only medial incisions are used along with saline hydro dissection. Dr. Michela mentioned that the common practice at her unit in Parma, Italy was to detach the muscle insertions, divide the aponeurosis and gently sweep the bundles more posteriorly from medial to lateral, till the Hamulus is reached.

The Hamulus is not fractured as in common in some units, but instead only the tensor tendon is cut. This prevents any fracture of the bone which has not shown to be of much benefit. The anatomical measurements of the Hamulus change with age, being smaller in children. However, as the patient ages beyond sixty, it becomes smaller, much like that of a child [7]. Our dear mentor for many years, Professor John B Mulliken of Children's hospital advised us to heed the warnings of Otto Kriens [8]. In his lessons on palate anatomy, Otto warned against rough handling of the Space of Ernst during palatal dissection, (Anatomy of the palate, Ralph Millard Cleft Craft Volume 3 p 50, 1976) which may cause paralysis of the nerve supply to the tensor and some anesthesia of the soft palate in some cases. Injury to the lesser palatine nerve causes paralysis of the muscles uvulae and anesthesia of the soft palate. Many senior plastic surgeons avoid the Space of Ernst.

The identification of the Hamulus position using this innovative marking system helps us to find the Space of Ernst easily, as it lies lateral to the hook. The palate structures can then be gently shifted medially, thereby easing repair as the flap are approximated without tension.

\section{Conflicts of Interest}

The authors declare that they have no conflicts of interest to disclose.

\section{Statement of Human and Animal Rights or Ethical Ap- proval}

This article does not contain any studies with human participants or animals by any of the authors. 


\section{Informed Consent}

For this type of study, informed consent is not required.

\section{Bibliography}

1. K Brusati and Nicola Manucci. "Repair of the cleft palate without lateral releasing incisions: report of 127 cases". Journal of Craniomaxillofacial Surgery 22 (1994): 138-143.

2. C Sommerlad., et al. "International Confederation for Cleft Lip and Palate and Related Craniofacial Anomalies Task Force Report: Palatoplasty in the Speaking Individual With Unrepaired Cleft Palate Brian". The Cleft Palate-Craniofacial Journal 51 (2014): e122-e128.

3. Isaac J., et al. "Intraoperative expansion of the palate by the tumescent technique” 100 (1997).

4. ALEX A KANE., et al. "The Effect of Hamulus Fracture on the Outcome of Palatoplasty: A Preliminary Report of a Prospective, Alternating Study Cleft Palate". Craniofacial Journal 37 (2000).

5. Reinhardt Putz and Alexander Kroyer. "Functional anatomy of the pterygoid Hamulus". Annals of Anatomy 181 (1999): 8588.

6. Kaan Orhan., et al. "Evaluation of the pterygoid hamulus morphology using cone beam computed tomography". Oral Surgery, Oral Medicine, Oral Pathology, Oral Radiology, and Endodontology 112 (2011): e48-e55.

7. Jelena Krmpotic., et al. "Relations of the pterygoid hamulus and hard palate in children and adults: Anatomical implications for the function of the soft palate". Annuals of Anatomy 188 (2006): 69-74.

8. Kriens OB. "An anatomical approach to veloplasty". Plastic and Reconstructive Surgery 43 (1969): 29-41.

\section{Assets from publication with us}

- Prompt Acknowledgement after receiving the article

- Thorough Double blinded peer review

- Rapid Publication

- Issue of Publication Certificate

- High visibility of your Published work

Website: www.actascientific.com/

Submit Article: www.actascientific.com/submission.php

Email us: editor@actascientific.com

Contact us: +919182824667 